\title{
KNOWLEDGE, ATTITUDE AND PRACTICE REGARDING COVID-19 AMONG HEALTHCARE WORKERS IN CHITWAN, NEPAL
}

Richa Nepal ${ }^{1,{ }^{*}}$, Kalyan Sapkota ${ }^{1}$, Pramod Paudel ${ }^{1}$, Bhojraj Adhikari', Kalidas Adhikari', Kiran Sapkota ${ }^{2}$, Rhishikesh Nepal ${ }^{3}$, Bishow Nath Adhikari ${ }^{4}$, Nabin Paudyal ${ }^{1}$

${ }^{1}$ Department of Internal Medicine, Bharatpur Hospital, Bharatpur, Nepal

${ }^{2}$ University of lowa, lowa City, lowa, United States of America

${ }^{3}$ University of Bentley, Boston, United States of America

${ }^{4}$ Department of Pediatrics, Kanti Children's Hospital, Kathmandu, Nepal

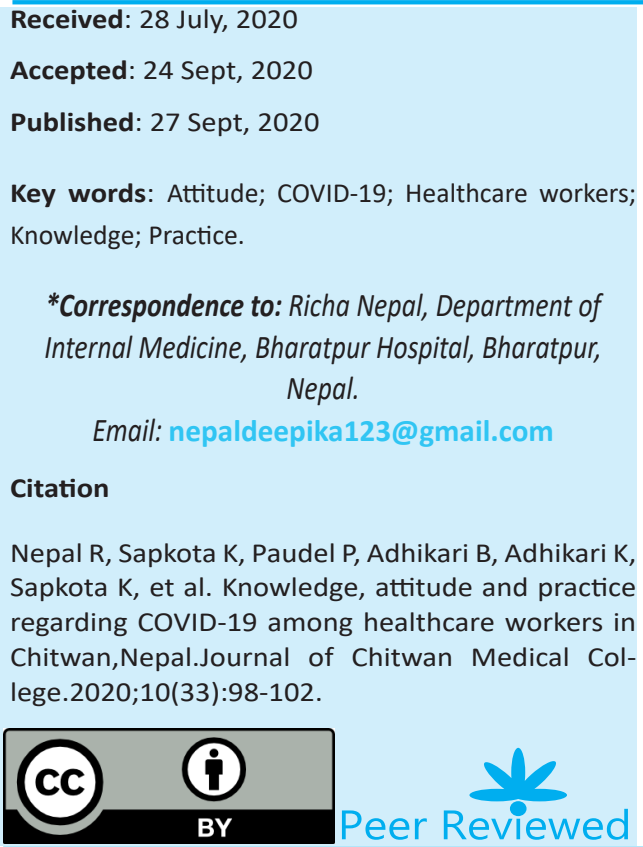

\section{INTRODUCTION}

Contagious diseases continue to terrorize and unsettle human populations worldwide. It was Herpes and Legionnaires' disease in the 1970 s to be followed by acquired immune deficiency syndrome (AIDS) and Ebola, then came the severe acute respiratory syndrome (SARS) in 2002, and now Coronavirus disease-2019 (COVID-19). ${ }^{1}$ Nepal was the first South Asian nation to have a confirmed COVID-19 case in a 32-year-old Wuhan returnee on 24th January, 2020. ${ }^{2}$

Bordering the world's two largest populations of India and China, Nepal is in a vulnerable state of possible health crisis today and needs strong strategic plans to fight COVID-19. Being ranked 111th among 195 countries on the Global Heath Security Index, 2019 and 150th in the 'detection and reporting' category, Nepal lags far behind the global average and is ill prepared to deal with the lurking epidemic of COVID-19. ${ }^{3}$

Preparedness to fight contagious diseases like COVID-19 starts with knowledge, positive attitude and safe practices. ${ }^{4}$ Thus, to facilitate the outbreak management of COVID-19 in Nepal, there is an urgent need to understand the awareness of COVID-19 among healthcare workers (HCWs). The purpose of this study was to assess knowledge, attitude, and practice (KAP) regarding COVID-19 among healthcare workers (HCWs) in Chitwan, one of the districts in central Nepal.

\section{METHODS}

This cross-sectional study was conducted over a span of two weeks from April 1st to April 14th, 2020, during the period when the Government of Nepal had imposed a nationwide lockdown to try to curtail the spread of COVID-19. Data was collected online through a survey form during the specified period. A questionnaire was circulated online which included questions related to knowledge, attitude and practice regarding COVID-19. The Institutional Review Committee of Bharatpur Hospital, Nepal, approved our study protocol prior to the formal survey. Healthcare workers above 16 years of age, from various hospitals and other health institutions in Chitwan, who agreed to participate in this study, were included. Different healthcare workers included doctors, nurses, health assistants (H.A), community medical assistants (C.M.A), pharmacists, medical lab technologists, radiographers, and medical microbiologists. Participants had to answer a yes-no question to con- 
firm their voluntary participation. After confirmation for participation, they were directed to complete the questionnaire.

Each correct answer/ positive attitude/ safe practice was scored 1 point and incorrect answer/ negative attitude/ unsafe practice/ I don't know was scored 0 points. Maximum knowledge/ attitude/ practice score was computed as 33, 13, and 20, respectively. An arbitrary system was used to classify scores: 0 to $<50 \%$ - poor, 50 to $<75 \%$ - moderate and $\geq 75 \%$ - good score. Attitude score of $\geq 50 \%$ was taken as positive and $<50 \%$ was taken as negative.

SPSS IBM version 25.0 was used for analysis. Descriptive statistics were presented using means and standard deviation for continuous variables, and frequencies and percentages for categorical variables. Knowledge, attitude, and practice scores were compared with different variables using independentsample t test, one-way analysis of variance (ANOVA), or Pearson's chi-square test as appropriate. Spearman's correlation was also computed between knowledge, attitude, and practice scores. The statistical significance level was set up at $p$ value < 0.05 . Cronbach's alpha was computed for reliability analysis of our questionnaire, which was calculated as 0.783 .

\section{RESULTS}

The study had 441 responders, out of which 353 samples were eligible for analysis. The majority of the respondents were fe- males (58.9\%), and most of the respondents were in age group of $16-29$ years $(67.1 \%)$. More than half of the respondents $(62.1 \%)$ had less than five years of work experience. Around $28.9 \%$ respondents were doctors, $47 \%$ were nurses, $11.6 \%$ were health assistants, and $2 \%$ were certified medical assistants. Around $10.5 \%$ patients included medical lab technologists, radiographers, pharmacists, and medical microbiologists (Table 1).

Table 1: Baseline characteristics of study population (N-353)

\begin{tabular}{|l|c|c|}
\hline $\begin{array}{l}\text { Baseline } \\
\text { characteristics }\end{array}$ & Subgroups & $\mathbf{n}(\%)$ \\
\hline \multirow{4}{*}{ Age } & 16 to 29 years & $237(67.1)$ \\
\cline { 2 - 3 } & 30 to 59 years & $115(32.6)$ \\
\cline { 2 - 3 } Gender & $\geq 60$ years & $1(0.3)$ \\
\hline \multirow{4}{*}{ Job Description } & Male & $145(41.1)$ \\
\cline { 2 - 3 } & Female & $208(58.9)$ \\
\cline { 2 - 3 } & Doctor & $102(28.9)$ \\
\cline { 2 - 3 } & Health assistant & $41(11.6)$ \\
\cline { 2 - 3 } & Nurse & $16(47)$ \\
\hline \multirow{3}{*}{ Work experience } & Others & $37(10.5)$ \\
\cline { 2 - 3 } & C.M.A & $7(2)$ \\
\cline { 2 - 3 } & < 5 years & $219(62)$ \\
\cline { 2 - 3 } & 5 10 years & $40(11.4)$ \\
\hline
\end{tabular}

Table 2: Knowledge, attitude and practice scores of the healthcare workers (N-353)

\begin{tabular}{|l|c|c|c|c|c|}
\hline Variables & Total score & Mean \pm S.D. & $\begin{array}{c}\text { Good score } \\
\mathbf{n}(\%)\end{array}$ & $\begin{array}{c}\text { Moderate score } \\
\mathbf{n}(\%)\end{array}$ & $\begin{array}{c}\text { Poor score } \\
\mathbf{n}(\%)\end{array}$ \\
\hline Knowledge score & 33 & $21.65 \pm 4.71$ & $108(30.6)$ & $182(51.6)$ & $63(17.8)$ \\
\hline Attitude score & 13 & $8.07 \pm 1.49$ & $53(15.0)$ & $242(68.6)$ & $58(16.4)$ \\
\hline Practice score & 20 & $13.89 \pm 5.33$ & $156(44.2)$ & $165(46.7)$ & $32(9.1)$ \\
\hline
\end{tabular}

Table 3: Analysis of KAP scores using Spearman's correlation coefficient

\begin{tabular}{|l|c|c|c|c|}
\hline Variables & Attitude & Knowledge & Practice \\
\hline \multirow{2}{*}{ Attitude } & Correlation coefficient $(r)$ & 1.000 & 0.074 & 0.238 \\
\cline { 2 - 4 } & p value &. & 0.167 & $0.000^{*}$ \\
\hline \multirow{2}{*}{ Knowledge } & Correlation coefficient $(r)$ & 0.074 & 1.000 & 0.476 \\
\cline { 2 - 4 } & p value & 0.167 &. & $0.000^{*}$ \\
\hline \multirow{2}{*}{ Practice } & Correlation coefficient $(r)$ & 0.238 & 0.476 & 1.000 \\
\cline { 2 - 4 } & p value & $0.000^{*}$ & $0.000^{*}$ &. \\
\hline
\end{tabular}

About 290 (82.2\%) healthcare workers obtained moderate to good knowledge scores, 295 (83.6\%) obtained moderate to good practice scores, and 321 (90.9\%) had positive attitude scores regarding COVID-19 (Table 2). The results of Spearman's correlation coefficient showed a positive correlation between knowledge and practice scores ( $r=0.476$, $p$ value- 0.000$)$ and a somewhat weaker positive correlation between attitude and practice scores ( $r=0.238, p$ - value 0.000 ) (Table 3 ).

Mean scores obtained by healthcare workers according to their job description in knowledge, attitude, and practice section are shown in Table 4.

The results of the bivariate analysis showed that higher mean knowledge scores were found among doctors $(23.70 \pm 4.48$, $p$ value- 0.000 ) as compared to other job descriptions of healthcare workers. Similarly, higher mean knowledge scores were also found in the male gender $(22.35 \pm 4.89$, p value -0.019$)$ and in the age group 30 to 59 years $(22.77 \pm 4.74$, $p$ value -0.006$)$. Higher mean attitude scores were found in the age group 30 to 50 years $(8.25 \pm 1.45, p-0.035)$ and in those with work experience of more than ten years $(8.35 \pm 1.70$, $p$ value -0.019$)$. 
Bivariate analysis also showed that the higher mean practice scores were found among health assistants (15.10 $\pm 3.61, p$ value -0.007$)$ as compared to other job descriptions, in the male gender (14.32 $\pm 3.45, p$ value -0.044$)$, and in healthcare workers with work experience of five to ten years (14.73 \pm 5.32 , $p$ value - 0.013) (Table 4).

Similarly, healthcare workers who had received training on infection prevention had better mean knowledge and practice scores ( $p$ value-0.007, 0.004, respectively). Healthcare workers who followed COVID-19 news daily had significantly bet- ter knowledge, attitude, and practice scores ( $p$ value -0.000 , 0.008 , and 0.000 , respectively) (Table 4). On analyzing confidence level of healthcare workers to deal with the pandemic to some of the pertinent questions in the knowledge and attitude sections, a significant association was found between confidence level and knowledge regarding the use of personal protective equipment ( $p$ value -0.007 ), knowledge regarding aerosol precautions to COVID-19 ( $p$ value -0.000 ), infection prevention training ( $p$ value -0.009 ), and attitude regarding sufficient institutional preparation ( $p$ value -0.044 ) (Table 5).

Table 4: Bivariate analysis of different variables with KAP scores of healthcare workers (N-353)

\begin{tabular}{|c|c|c|c|c|}
\hline Variables & & $\begin{array}{l}\text { Knowledge } \\
\text { (Mean士SD) }\end{array}$ & $\begin{array}{c}\text { Attitude } \\
\text { (Mean士SD) }\end{array}$ & $\begin{array}{c}\text { Practice } \\
\text { (Mean } \pm S D)\end{array}$ \\
\hline \multirow{3}{*}{ Gender } & Male & $22.35 \pm 4.89$ & $8.15 \pm 1.61$ & $14.32 \pm 3.45$ \\
\hline & Female & $21.15 \pm 4.53$ & $8.00 \pm 1.40$ & $13.59 \pm 3.21$ \\
\hline & $p$-value & 0.019* & 0.364 & $0.044^{*}$ \\
\hline \multirow{4}{*}{ Age } & $16-29$ years & $21.09 \pm 4.61$ & $7.99 \pm 1.49$ & $13.76 \pm 3.41$ \\
\hline & 30 to 59 years & $22.77 \pm 4.74$ & $8.25 \pm 1.45$ & $14.23 \pm 3.09$ \\
\hline & $\geq 60$ years & $24.00 \pm 0.0$ & $5.00 \pm 0.00$ & $7.00 \pm 0.00$ \\
\hline & $\mathrm{p}$-value & $0.006^{*}$ & $0.035^{*}$ & 0.054 \\
\hline \multirow{6}{*}{ Job description } & Doctor & $23.70 \pm 4.48$ & $8.04 \pm 1.32$ & $14.30 \pm 3.13$ \\
\hline & Nurse & $21.02 \pm 4.53$ & $7.90 \pm 1.45$ & $13.52 \pm 3.26$ \\
\hline & H.A & $21.49 \pm 4.24$ & $8.39 \pm 1.57$ & $15.10 \pm 3.61$ \\
\hline & C.M.A & $20.00 \pm 5.41$ & $8.29 \pm 1.97$ & $11.14 \pm 4.48$ \\
\hline & Others & $19.30 \pm 4.61$ & $8.49 \pm 1.82$ & $13.57 \pm 3.14$ \\
\hline & $p$-value & $0.000 *$ & 0.127 & $0.007^{*}$ \\
\hline \multirow{4}{*}{ Work experience } & $<5$ years & $21.27 \pm 4.68$ & $7.89 \pm 1.45$ & $13.53 \pm 3.32$ \\
\hline & 5 to 10 years & $22.31 \pm 4.70$ & $8.35 \pm 1.43$ & $14.73 \pm 5.32$ \\
\hline & $>10$ years & $22.55 \pm 4.79$ & $8.35 \pm 1.70$ & $13.88 \pm 3.09$ \\
\hline & $p$-value & 0.148 & 0.019* & $0.013^{*}$ \\
\hline \multirow{3}{*}{ Infection prevention training } & Yes & $23.44 \pm 4.69$ & $8.16 \pm 1.92$ & $13.70 \pm 3.29$ \\
\hline & No & $21.40 \pm 4.66$ & $8.05 \pm 1.42$ & $15.26 \pm 3.29$ \\
\hline & p-value & $0.007^{*}$ & 0.648 & 0.04* \\
\hline \multirow{3}{*}{ Follow COVID-19 news } & Sometimes & $20.19 \pm 5.79$ & $6.73 \pm 1.50$ & $12.51 \pm 3.61$ \\
\hline & Daily & $21.94 \pm 4.41$ & $8.33 \pm 1.34$ & $14.17 \pm 3.20$ \\
\hline & $p$-value & 0.009* & $0.000 *$ & $0.000 *$ \\
\hline
\end{tabular}

Table 5: Association of confidence to handle COVID-19 by HCWs to different variables

\begin{tabular}{|c|c|c|c|c|c|c|c|c|}
\hline \multirow{2}{*}{ Confidence level } & \multicolumn{2}{|c|}{$\begin{array}{l}\text { Received infection } \\
\text { prevention training }\end{array}$} & \multicolumn{2}{|c|}{$\begin{array}{l}\text { Knows how to } \\
\text { use PPE }\end{array}$} & \multicolumn{2}{|c|}{$\begin{array}{l}\text { Sufficient institutional } \\
\text { preparation }\end{array}$} & \multicolumn{2}{|c|}{$\begin{array}{l}\text { Knowledge about } \\
\text { aerosol precautions }\end{array}$} \\
\hline & Yes & No & Yes & No & Yes & No & Yes & No \\
\hline Not at all & 7 & 95 & 57 & 45 & 19 & 83 & 50 & 52 \\
\hline To some extent & 20 & 159 & 126 & 53 & 28 & 149 & 81 & 98 \\
\hline To considerable extent & 14 & 42 & 43 & 13 & 17 & 39 & 43 & 13 \\
\hline To great extent & 2 & 14 & 14 & 2 & 7 & 9 & 14 & 2 \\
\hline$(\mathrm{N}-353)$ & 43 & 310 & 240 & 113 & 71 & 282 & 188 & 165 \\
\hline$p$-value & \multicolumn{2}{|c|}{$0.009 *$} & \multicolumn{2}{|c|}{$0.007^{*}$} & \multicolumn{2}{|c|}{$0.044^{*}$} & \multicolumn{2}{|c|}{$0.000 *$} \\
\hline
\end{tabular}




\section{DISCUSSION}

In our study, the vast majority of healthcare workers practicing in Chitwan had moderate to good knowledge and practice scores, and had a positive attitude towards COVID-19 (Table 1). These findings may be due to the fact that the study was conducted during the early stage of this pandemic, when the entire health system and healthcare workers were being prepared to deal with the possible surge of COVID-19 cases in Nepal. The findings were similar to a study done by Saqlain et al., where $93.2 \%$ respondents had good knowledge, positive attitude, and $88.7 \%$ of them had good practice towards COVID-19. ${ }^{5}$ Similarly, Zhou et al. also reported that the majority of HCWs in a study in China had sufficient knowledge and good practice scores regarding COVID-19 (89\%, 89.7\%, respectively). ${ }^{6}$

Doctors followed by health assistants were found to have higher mean knowledge scores as compared to other job descriptions in our study and health assistants followed by doctors had higher mean practice scores (Table 4). These findings were somewhat different from a study by Zhou et al., where doctors followed by nurses had better knowledge scores as compared to other HCWs. ${ }^{6}$ On correlation analysis in our study, knowledge and attitude scores were positively correlated with practice scores (Table 3). A similar positive correlation between attitude and practice scores was also seen in a study regarding COVID-19 by Peng et al. $(r=0.319$, $p$ value $<0.001) .{ }^{7}$ Saqlain et al. also reported positive linear correlation between knowledge and practice scores ( $r=0.142, p$ value- 0.016$)$, and between attitude and practice scores $(r=0.174, p$ value- 0.004$)$ in their study. ${ }^{5}$ The right knowledge, along with the right attitude, can eventually lead to safe practices and healthy behaviors. ${ }^{8}$ These findings clearly emphasize the need to improve COVID-19 knowledge among HCWs through different means and develop a positive attitude to promote safe practices and control measures eventually.

Age, gender, and type of job description were significantly associated with better knowledge scores in this study; whereas work experience was not found to have any significant association to knowledge scores (Table 4). Association of the job description to knowledge scores was also reported in a study by Giao et al. ${ }^{9}$ However, the association of age and gender to knowledge score in our study could have resulted due to the fact that the majority of doctors and health assistants were males (82.35\%, 78.04\%, respectively) and most of the doctors $(58.8 \%)$ were in the age group of 30 to 59 years. There was no significant association of job description to attitude scores in our study, which was different from the finding by Giao et al. ${ }^{9}$

Infection prevention training was significantly associated with better knowledge and practice scores in our study (Table 4). Likewise, the regular following of COVID-19 news by healthcare workers was an important factor significantly associated with higher knowledge, attitude, and practice scores (Table 4). About 75.9\% healthcare workers used official national and international sites as their source of information in our study. A similar finding was also seen in a study by Asaad et al., regard- ing middle east respiratory syndrome (MERS), where majority of HCWs (50\%) used the Ministry of Health website as a source of information for MERS. ${ }^{10}$ This finding sets greater responsibility on health care authorities to increase the accessibility of educational materials to HCWs by various modes of information delivery. ${ }^{10}$ Around $67 \%$ HCWs in our study also used social media as a source of information. Saqlain et al. reported that $87.7 \%$ of respondents in their study relied on social media for information on COVID-19. ${ }^{5}$ This is a matter of considerable concern as the internet and social media have a sea of unverified information that can misguide HCWs. Thus, HCWs should practice meticulous evaluation of related information present in social media. ${ }^{11,12}$

Aerosol generating procedures, in a suspected or confirmed COVID-19 patient, need to be done with additional infection control measures like performing the procedure with least number of health personnel in a single room, using the most qualified personnel, and use of personal protective equipment (PPE). ${ }^{13}$ Aerosol generating procedures are not just limited to tracheal intubation, rather also involve procedures like nebulization, sputum induction, chest physiotherapy, airway suction and cardio-pulmonary resuscitation. ${ }^{13}$ Around $46.7 \%$ health care workers in this study did not know about precautions to be taken during aerosol generating procedures, which could have disastrous consequences on the safety of health care professionals. ${ }^{14}$ Likewise, nearly $75.9 \%$ respondents did not believe that there was sufficient institutional preparation for dealing with COVID-19, and about $91.5 \%$ respondents said that there were no sufficient medical supplies in their health setup to fight against COVID-19. 32\% health care workers did not know how to use personal protective equipment, and $87.8 \%$ of them did not have any infection prevention training.

In our study, only $20.4 \%$ healthcare workers believed that they were considerably or greatly confident to handle the COVID-19 outbreak in their healthcare setup. Confidence of healthcare workers was found to be significantly associated with infection prevention training ( $p$ value -0.009 ), attitude regarding sufficient institutional preparation in their healthcare setup ( $p$ value -0.044$)$, knowledge regarding aerosol precautions to COVID-19 ( $p$ value -0.000 ) and knowledge regarding the use of personal protective equipment ( $p$ value- 0.007 ) (Table 5). Similarly, in a study regarding the Ebola virus disease by Iliyasu et al., such a negative attitude was related to lack of knowledge about the use of PPE and the shortage of PPE. ${ }^{15}$ Thus, this undesirable finding of poor attitude of HCWs towards a highly infectious disease like COVID-19, must be addressed by concerned authorities by the provision of sustained supply of PPE while augmenting education on infection prevention and control practices. Added work incentives, insurance policy, job security and provision for families of HCWs, are other motivational approaches that must be explored by policy-makers to inspire greater confidence among HCWs. ${ }^{15}$

The main limitation of this study was that it was based on a self-reported questionnaire, which may be susceptible to selfpresentation bias. The study included heterogeneous group of 
healthcare workers with different educational background and professional experience. Thus, the results regarding knowledge, attitude and practice scores, could not be generalized to every group of healthcare worker.

\section{CONCLUSION}

In summary, the majority of healthcare workers in Chitwan, $\mathrm{Ne}$ pal had moderate to good knowledge and practice scores, and had a positive attitude towards COVID-19. However, the majority of HCWs did not believe that they were confident to handle this outbreak in their healthcare setup. Furthermore, there was a significant association between knowledge, attitude, and practice scores, which highlights the need to strengthen knowledge regarding COVID-19 among healthcare workers through different means to develop a more optimistic attitude and promote safe practices to fight against this novel disease.

\section{ACKNOWLEDGEMENT}

We thank all the healthcare workers who had participated in this study.

\section{CONFLICT OF INTEREST: None}

FINANCIAL DISCLOSURE: None

\section{REFERENCES:}

1. Jones DS. History in a crisis-lessons for Covid-19. New England Journal of Medicine. 2020 Apr 30;382(18):1681-3. [DOI]

2. Bastola A, Sah R, Rodriguez-Morales AJ, Lal BK, Jha R, Ojha HC, et al. The first 2019 novel coronavirus case in Nepal. The Lancet Infectious Diseases. 2020 Mar 1;20(3):279-80. [DOI]

3. Open Philantrophy Project. Global health Security index: Building collective action and accountability.2019 [cited on 2020 July 23]. Available from: [LINK]

4. World Health Organization. A Guide to Developing Knowledge, Attitude and Practice Surveys, 2008. Available from: [LINK]

5. Saqlain M, Munir MM, ur Rehman S, Gulzar A, Naz S, Ahmed Z, et al. Knowledge, attitude, practice and perceived barriers among healthcare professionals regarding COVID-19: A Cross-sectional survey from Pakistan. Journal of Hospital Infection. 2020 May 11. [DOI]

6. Zhou M, Tang F, Wang Y, Nie H, Zhang L, You G, et al. Knowledge, attitude and practice regarding COVID-19 among health care workers in Henan, China. Journal of Hospital Infection. 2020 Apr 9. [DOI]

7. Peng $\mathrm{Y}$, Pei $\mathrm{C}$, Zheng $\mathrm{Y}$, Wang J, Zhang K, Zheng Z, et al. Knowledge, attitude and practice associated with COVID-19 among university students: a cross-sectional survey in China. [DOI]

8. World Health Organization. A Guide to Developing Knowledge, Attitude and Practice Surveys, 2008.Available from: [LINK]
9. Giao H, Han NT, Van Khanh T, Ngan VK, Van Tam V, Le An P. Knowledge and attitude toward COVID-19 among healthcare workers at District $2 \mathrm{Hospi}$ tal, Ho Chi Minh City. Asian Pac J Trop Med. 2020;13. [DOI]

10. Asaad AM, El-Sokkary RH, Alzamanan MA, El-Shafei M. Knowledge and attitudes towards Middle East respiratory syndrome-coronavirus (MERSCoV) among health care workers in south-western Saudi Arabia. East Mediterr Health J. 2019;25. [DOI]

11. Meyer B, García-bocanegra I, Wernery U, Wernery R, Sieberg A, Müller $M A$, et al. Serologic Assessment of Possibility for MERS-CoV Infection in Equids Autochthonous Dengue Fever Imported to England from Japan 2014. 2015;21(1):20-1. [DOI]

12. ALdowyan N, Abdallah AS, El-Gharabawy R. Knowledge, Attitude and Practice (KAP) Study about Middle East Respiratory Syndrome Coronavirus (MERS-CoV) among Population in Saudi Arabia. International Archives of Medicine. 2017;10:1-12. [DOI]

13. CSG-Clinical care. COVID-19 Guidance on Aerosol Generating Procedures During COVID-19 Outbreak. 2020;1-5. Available from: [LINK]

14. Tran K, Cimon K, Severn M, Pessoa-Silva CL, Conly J. Aerosol generating procedures and risk of transmission of acute respiratory infections to healthcare workers: a systematic review. PloS one. 2012;7(4). [DOI]

15. Iliyasu G, Ogoina D, Otu AA, Dayyab FM, Ebenso B, Otokpa D, et al. A multi-site knowledge attitude and practice survey of Ebola virus disease in Nigeria. PloS one. 2015;10(8). [DOI] 